\title{
SISTEM PENGAMBILAN KEPUTUSAN MULTI KRITERIA PADA INDUSTRI JASA UNTUK MENINGKATKAN DAYA SAING USAHA DALAM MENGHADAPI MASYARAKAT EKONOMI ASEAN MENGGUNAKAN MINIMUM DEVIATION METHOD (Studi Kasus Di CV. Transpatindo, Berbah, Sleman, DIY)
}

\author{
Gunawan Madyono Putro \\ Fakultas Teknik Industri, Jurusan Teknik Industri \\ Universitas Pembangunan Nasional 'Veteran' Yogyakarta \\ Jalan Babarsari 2, Tambakbayan, Yogyakarta, 55281 \\ jur_tiupn@telkom.net
}

\begin{abstract}
CV. Transpatindo is a company engaged in the delivery of goods. To improve the competitiveness of enterprises in the era of the Asean Economic Community, which opened in 2016, then the company needs to improve customer satisfaction in order to service customers more loyal CV. Transpatindo. To improve customer satisfaction will certainly increase operating costs, so as not to decrease the competitiveness of enterprises it is necessary to minimizing operational costs. This study aims to maximize customer satisfaction with each mempertimbangka to minimize the cost operasional.Upaya to maximize customer satisfaction with still consider to minimize the operational cost is the problem of multi-criteria decision making, because maximizing customer satisfaction and minimize production costs are two conflicting objective functions ( contradictory). To find a compromise solution between the two functions of these objectives will be done using the minimum deviation method. Steps to resolve the problem using the minimum deviation method is to determine the ideal solution each objective function, create tables payoffnya, create a mathematical model of permasalahn solved using the minimum deviation method, completed the mathematical model to obtain a compromise solution of two conflicting objective functions. A compromise solution that is obtained is the value of customer satisfaction is 4.9 which is ideally a value of 6. Operating cost per day is US \$2.116 million, - where the value of the ideal is Rp 1.250.000, -. Weight of packets sent per day are shipped per day A package weighing $100 \mathrm{~kg}$, B packages shipped per day weighing $50 \mathrm{~kg}$, and packet $C$ are sent per day weighing $20 \mathrm{~kg}$.
\end{abstract}

Keywords: multi-criteria decision making, a compromise solution, the minimum deviation method

Abstrak
CV. Transpatindo adalah perusahaan yang bergerak dalam jasa pengiriman barang. Untuk
meningkatkan daya saing usaha dalam menghadapi era Masyarakat Ekonomi Asean yang
mulai dibuka pada tahun 2016, maka perusahaan perlu untuk meningkatkan kepuasan
pelanggan agar pelanggan semakin loyal terhadap pelayanan CV. Transpatindo. Untuk
meningkatkan kepuasan pelanggan tentunya akan meningkatkan biaya operasional, agar daya
saing perusahaan tidak menurun maka perlu dilakukan minimasi biaya operasional. Penelitian
ini bertujuan untuk memaksimasi kepuasan pelanggan dengan masing mempertimbangka
untuk meminimasi biaya operasional.Upaya untuk memaksimasi kepuasan pelanggan dengan
masih mempertimbangkan untuk meminimasi biaya operasional adalah permasalahan
pengambilan keputusan multi criteria, karena maksimasi kepuasan pelanggan dan meminimasi
biaya produksi adalah dua fungsi tujuan yang saling berkonflik (kontradiktif). Untuk mencari
solusi kompromi diantara dua fungsi tujuan tersebut akan dilakukan dengan menggunakan
minimum deviation method. Langkah penyelesaian permasalahan menggunakan minimum
deviation method adalah menentukan solusi ideal masing-masing fungsi tujuan, membuat tabel
payoffnya, membuat model matematika dari permasalahn yang diselesaikan menggunakan
minimum deviation method, menyelesaikan model matematika tersebut untuk mendapatkan


solusi kompromi dari dua fungsi tujuan yang saling berkonflik. Solusi kompromi yang didapatkan adalah nilai kepuasan pelanggan adalah 4,9 dimana nilai idealnya adalah 6 . Biaya operasional per hari adalah $\mathrm{Rp} 2.116 .000$,- dimana nilai idealnya adalah $\mathrm{Rp} 1.250 .000,-$. Berat paket yang dikirimkan per hari adalah paket A dikirimkan per hari seberat $100 \mathrm{~kg}$, paket $B$ dikirimkan per hari seberat $50 \mathrm{~kg}$, dan paket $C$ dikirimkan per hari seberat $20 \mathrm{~kg}$.

Kata kunci : pengambilan keputusan multi criteria, solusi kompromi, minimum deviation method

\section{PENDAHULUAN}

\subsection{Latar Belakang}

Masyarakat Ekonomi Asean merupakan suatu tatanan ekonomi baru yang diterapkan di kawasan Asia Tenggara yang mengikat negara-negara anggota Asean untuk membuka ekonomi negaranya terhadap ekspansi yang dilakukan oleh negara-negara sesama anggota Asean. Masyarakat Ekonomi Asean mulai diterapkan pada tahun 2016. Masyarakat Ekonomi Asean merupakan tantangan sekaligus peluang bagi pelaku usaha di Indonesia. Masyarakat Ekonomi Asean merupakan tantangan karena pelaku usaha harus bersaing dengan pelaku usaha lain dari negara tetangga, sedangkan sebagai peluang karena dengan adanya Masyarakat Ekonomi Asean maka pelaku usaha di Indonesia juga dapat melakukan ekspansi usaha ke negara-negara anggota Asean.

Industri di Indonesia baik itu industri jasa, industri manufaktur, maupun industri proses harus bersiap untuk menghadapai Masyarakat Ekonomi Asean. Industri jasa yang produknya berupa jasa yang bersifat intangible harus meningkatkan produk jasanya dan mengoptimalkan semua tujuan usahanya. Peningkatan produk jasa yang bersifat intangible tentunya lebih sukar untuk diukur pencapaiannya, oleh karena itu perlu di bangun suatu sistem pengambilan keputusan untuk mengukur peningkatan tersebut.

CV. Transpatindo adalah perusahaan yang bergerak pada bidang jasa pengiriman barang. CV. Transpatindo harus meningkatkan daya saing usahanya dengan melakukan optimasi terhadap tujuan perusahaan yang telah ditetapkan sebagai usaha menjaga dan meningkatkan eksistensi diri dalam menghadapi Masyarakat Ekonomi Asean. CV. Transpatindo mempunyai tujuan untuk selalu meningkatkan tingkat kepuasan pelanggan sehingga pelanggan menjadi loyal. Peningkatan kepuasan pelanggan pastinya memerlukan biaya operasional yang tidak sedikit, sedangkan agar dapat bersaing di era Masyarakat Ekonomi Asean perusahaan harus meningkatkan efisiensi. Untuk meningkatkan efisiensi maka perusahaan berkeinginan untuk meminimalkan biaya operasional. Tujuan perusahaan untuk memaksimalkan kepuasaan pelanggan akan menyebabkan peningkatan biaya operasional perusahaan, padahal perusahaan juga bertujuan untuk meminimalkan biaya operasional. Tujuan perusahaan untuk memaksimalkan kepuasan pelanggan dan meminimalkan biaya operasional merupakan dua tujuan perusahaan yang saling kontradiktif , dimana hal tersebut termasuk dalam permasalahan pengambilan keputusan multi criteria.

Pengambilan keputusan terhadap dua tujuan atau lebih yang saling kontradiktif merupakan permasalahan pengambilan keputusan multi criteria. Pada penelitian ini akan dilakukan pengembangan model pengambilan keputusan multi criteria untuk melakukan optimasi terhadap dua tujuan CV. Transpatindo yang saling kontradiktif. Penelitian ini akan membantu CV. Transpatindo dalam melakukan pengambilan keputusan terhadap dua tujuan perusahaannya yang saling kontradiktif agar dapat meningkatkan kepuasan pelanggan dan sekaligus melakukan efisiensi sehingga meningkat daya saingnya untuk berkompetisi di era Masayarakat Ekonomi Asean.

Untuk melakukan optimasi terhadap dua tujuan CV. Transpatindo yang saling kontradiktif dilakukan menggunakan salah satu metode yang terdapat pada pengambilan keputusan multi criteria, yaitu minimum deviation method. Hasil dari optimasi adalah didapatkan nilai trade-off dari dua tujuan perusahaan yang saling kontradiktif. Penelitian ini menggunakan minimum deviation method untuk mencari nilai trade-off dari dua tujuan perusahaan yang saling kontradiktif, karena metode ini lebih presisi dalam mencari nilai trade-off dari dua tujuan atau 
lebih. Kepresisian minimum deviation method dalam mencari nilai trade-off lebih baik dari pada metode-metode pengambilan keputusan multi criteria yang lain karena berusaha untuk meminimumkan deviasi nilai trade-off yang dihasilkan terhadap nilai idealnya, sehingga nilai trade-off yang didapatkan lebih presisi karena diusahakan mempunyai deviasi sekecil mungkin terhadap nilai idealnya.

\subsection{Perumusan Masalah}

Berdasarkan uraian di atas maka masalah yang diangkat dalam penelitian ini adalah bagaimana membangun sistem pengambilan keputusan multi kriteria di industri jasa CV. Transpatindo untuk meningkatkan daya saing usaha dalam menghadapi Masyarakat Ekonomi Asean menggunakan minimum deviation method.

\subsection{Batasan Masalah}

Agar pembahasan masalah lebih fokus terhadap permasalahan yang telah dirumuskan maka dilakukan pembatasan masalah sebagai berikut:

1. Sistem pengambilan keputusan yang dibangun merupakan model optimasi terhadap dua tujuan perusahaan yang saling kontradiktif dengan batasan berupa pembatasan sumber daya dalam melakukan pencapaian tujuan perusahaan.

2. Dua tujuan perusahaan yang saling bertentangan yang menjadi perhatian dalam penelitian ini adalah maksimasi kepuasan pelanggan dan minimasi biaya operasional perusahaan.

\subsection{Tujuan Penelitian}

Tujuan dari penelitian ini adalah membangun sistem pengambilan keputusan multi kriteria pada industri jasa CV. Transpatindo sehingga dapat membantu manajemen perusahaan dalam mengambil keputusan mengenai dua tujuan perusahaan yang saling kontradiktif menggunakan minimum deviation method.

\section{METODOLOGI PENELITIAN}

\subsection{Objek Penelitian}

Obyek penelitian adalah industri jasa pengiriman barang CV. Transpatindo. Penelitian ini mengembangkan sistem pengambilan keputusan multi kriteria dengan objek penelitian di industri jasa pengiriman barang CV. Transpatindo untuk meningkatkan daya saing usaha dalam menghadapi Masyarakat Ekonomi Asean. Tool yang digunakan untuk melakukan pengambilan keputusan multi criteria pada penelitian ini adalah minimum deviation method.

\subsection{Teknik pengumpulan data}

Untuk mendapatkan hasil yang memuaskan tentang gambaran suatu persoalan dalam suatu penelitian, diperlukan pengumpulan data-data. Berdasarkan macamnya data dibagi menjadi 2 yaitu:

1. Data primer

Data primer didapatkan peneliti melalui wawancara dengan pihak CV. Transpatindo.

2. Data Sekunder

Data ini berupa data-data perusahaan yang digunakan untuk membangun model pengambilan keputusan multi criteria di CV. Transpatindo. 


\subsection{Kerangka Penelitian}

Langkah-langkah penelitian ini dapat dilihat pada kerangka penelitian Gambar.1

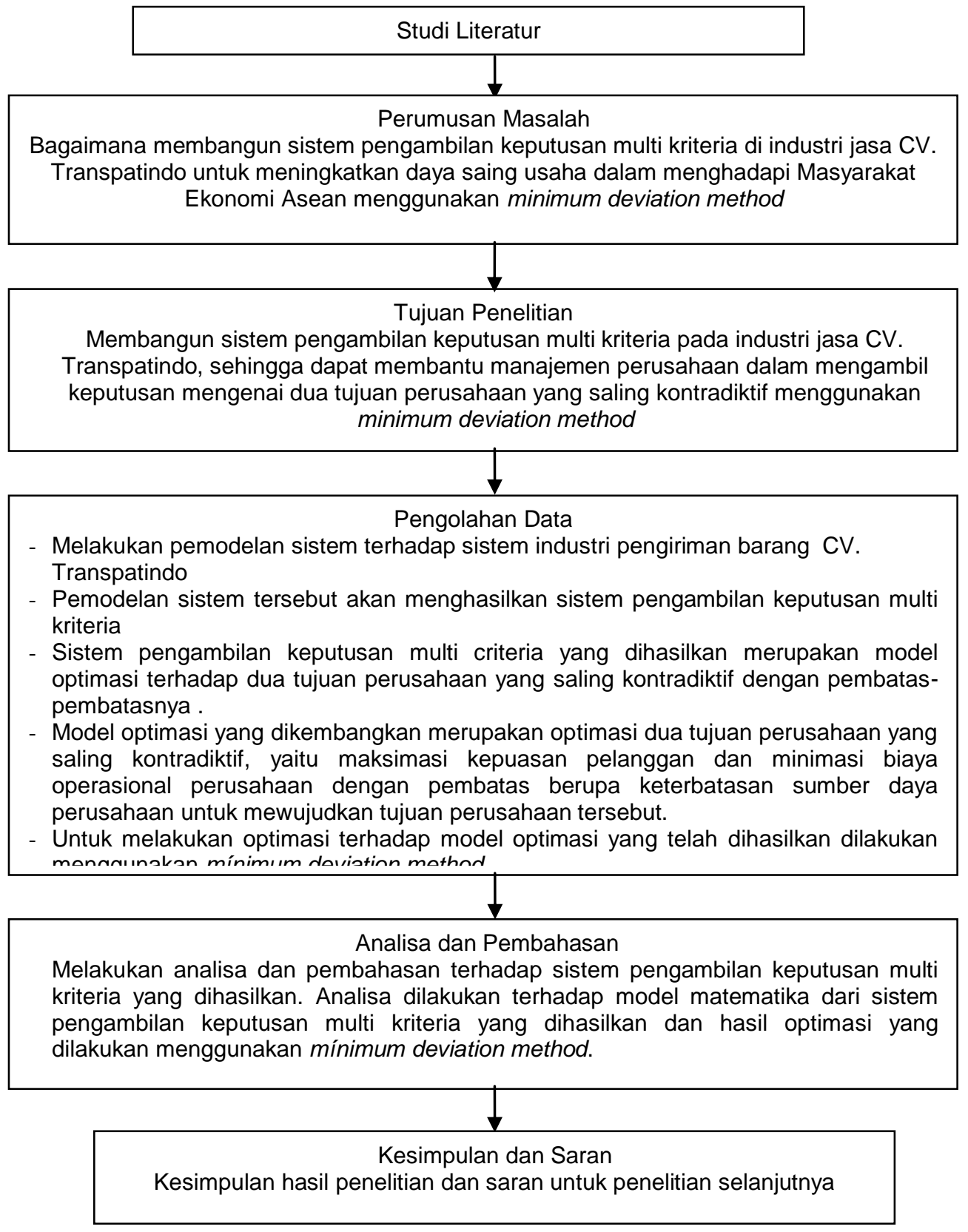

Gambar 1. Kerangka Penelitian

\section{PENGOLAHAN DATA DAN ANALISA HASIL}

\subsection{Pengumpulan Data}

Data-data yang diperlukan untuk mengembangkan model pengambilan keputusan multi kriteria di CV. Transpatindo dengan fungsi tujuan maksimasi kepuasan pelanggan dan minimasi biaya operasional perusahaan adalah data kapasitas tenaga kerja, data ketersediaan jam kerja, data banyaknya job,data waktu pengiriman, data biaya pengiriman barang, data kontribusi kepuasan pelanggan pada setiap jenis barang yang dikirim .

\subsection{Pengolahan Data}

Data-data yang sudah dikumpulkan akan dilakukan pengolahan data dengan melakukan perhitungan biaya produksi dan perhitungan kapasitas jam kerja. 


\subsection{Pengembangan Sistem Pengambilan Keputusan Multi Kriteria}

Sistem pengambilan keputusan multi criteria yang dikembangkan merupakan model matematika yang terdiri dari dua fungsi tujuan dan pembatas yang membatasi pencapaian dua fungsi tujuan yang ada. Model matematika tersebut merupakan hasil pemodelan system dan pemodelan matematika pada system nyata di CV. Transpatindo. Tahap-tahap pengembangan system pengambilan keputusan multi criteria dalam persoalan ini adalah:

1. Menentukan variable keputusan

Variabel keputusan disini adalah berat tiga barang yang paling sering dikirim oleh CV.

Transpatindo dalam setiap harinya. Variabel keputusan tersebut adalah:

$\mathrm{x}_{1}=$ berat paket $A$ yang dikirim per hari ( puluh $\mathrm{kg}$ )

$\mathrm{x}_{2}=$ berat paket $\mathrm{B}$ yang dikirim per hari (puluh $\mathrm{kg}$ )

$\mathrm{x}_{3}=$ berat paket $\mathrm{C}$ yang dikirim per hari (puluh $\mathrm{kg}$ )

2. Menentukan fungsi tujuan

Fungsi tujuan dari model matematika pengambilan keputusan multi criteria ini adalah maksimasi kepuasan pelanggan dan minimasi biaya operasional. Formulasi fungsi tujuannya adalah sebagai berikut:

Maksimasi $Z_{1}=f_{1}(X)=0,25 x_{1}+0,30 x_{2}+0,45 x_{3}$

Minimasi $Z_{2}=f_{1}(X)=-125000 x_{1}+112000 x_{2}+153000 x_{3}$

3. Menentukan fungsi pembatas

a. Batasan berat barang yang dikirim dalam satu kali pengiriman

Batasan ini mempunyai formulasi matematika sebagai berikut:

$X_{1}+X_{2}+X_{3} \leq 1500$

b. Batasan ketersediaan jam kerja

Batasan waktu proses mempunyai formulasi matematika sebagai berikut:

$15,57 X_{1}+19,24 X_{2}+20,64 X_{3} \leq 900$

c. Batasan ketersediaan jumlah tenaga kerja

Formulasi matematika untuk batasan jumlah tenaga kerja adalah sebagai berikut:

$2 X_{1}+X_{2}+3 X_{3} \leq 20$

d. Batasan non negative

Suatu batasan yang menyatakan bahwa berat barang yang dikirim tidak mungkin negative. Batasan non negative adalah:

$\mathrm{X}_{1}, \mathrm{X}_{2}, \mathrm{X}_{3} \geq 0$

4. Menentukan solusi kompromi dari model matematika dari system pengambilan keputusan multi criteria yang dibangun menggunakan minimum deviation method.Langkah-langkah penyelesaian dalam menyelesaikan permasalahan multi criteria menggunakan minimum deviation method adalah sebagai berikut:

a. Tentukan solusi ideal masing-masing fungsi tujuan

Solusi ideal masing-masing fungsi tujuan dicari dengan metode simpleks

menggunakan software winQSB. Solusi ideal masing-masing fungsi tujuan adalah:

$$
\begin{aligned}
Z_{1 *}^{*} & =Z_{1} \text { maksimal }=6 \text { dengan } x^{1^{*}}=(0,20,0) \\
Z_{2}^{*} & =Z_{2} \text { minimal }=-1250000 \text { dengan } x^{2^{*}}=(10,0,0) \\
& =Z_{2} \text { maksimal }=-Z_{2} \text { minimal }=-(-1250000)=1250000
\end{aligned}
$$

b. Buat tabel payoff

\begin{tabular}{c|c|c|}
\multicolumn{1}{c}{} & \multicolumn{1}{c}{$x^{1^{*}}$} & \multicolumn{1}{c}{$x^{2^{*}}$} \\
\cline { 3 - 3 }$Z_{1}$ & 6 & 2,5 \\
\cline { 2 - 3 }$Z_{2}$ & -224000 & 125000 \\
\cline { 2 - 3 } & &
\end{tabular}

c. Model matematika dari persoalan multi criteria yang diselesaikan menggunakan minimum deviation method

Minimasi $z=\left(\frac{6-\left(0,25 x_{1}+0,30 x_{2}+0,45 x_{3}\right)}{6-2,5}\right)+\left(\frac{1250000-\left(125000 x_{1}-112000 x_{2}-153000 x_{3}\right)}{1250000-(-2240000)}\right)$

Pembatas

$$
\begin{aligned}
& X_{1}+X_{2}+X_{3} \leq 1500 \\
& 15,57 X_{1}+19,24 X_{2}+20,64 X_{3} \leq 900 \\
& 2 X_{1}+X_{2}+3 X_{3} \leq 20 \\
& X_{1}, X_{2}, X_{3} \geq 0
\end{aligned}
$$


Solusinya:

$Z^{*}=1,1$ dengan $x^{\prime}=(10,5,2)$

Sehingga solusi kompromi yang didapatkan adalah:

$$
\begin{aligned}
& Z_{1}=4,9 \\
& Z_{2}=2116000
\end{aligned}
$$

5. Analisa Hasil

Solusi kompromi menggunakan minimum deviation methodadala $Z_{1}=4,9$ (nilai kepuasan pelanggan adalah 4,9) dan $Z_{2}=2116000$ (biaya operasional per hari adalah $R p$ 2.116.000) dengan $X_{1}=10$ (berat paket $A$ yang dikirim per hari adalah $100 \mathrm{~kg}$ ), $X_{2}=5$ (berat paket $B$ yang dikirim per hari adalah $50 \mathrm{~kg}$ ), serta $X_{3}=2$ (berat paket $C$ yang dikirim per hari adalah $20 \mathrm{~kg}$ ). Nilai kepuasan pelanggan sebesar 4,9 sedikit lebih kecil jika dibandingkan dengan nilai kepuasan pelanggan ideal sebesar 6 , demikian juga biaya operasional per hari Rp 2.116.000,- sedikit lebih besar dari pada biaya operasional ideal sebesar $\mathrm{Rp} 1.250 .000,-$, hal tersebut sesuai dengan kaidah trade off atau solusi kompromi dari permasalahan pengambilan keputusan multi criteria. Dengan mengoptimasi dua fungsi tujuan, yaitu maksimasi kepuasan pelanggan dan minimasi biaya operasional maka manajemen sudah berusaha untuk menaikkan daya saing usahanya dalam rangka menghadapi era masyarakat ekonomi asean.

\section{KESIMPULAN DAN SARAN}

Sistem pengambilan keputusan multi kriteria menggunakan minimum deviation method telah dapat membantu manajemen $\mathrm{CV}$. Transpatindo dalam meningkatkan daya saing usahanya melalui maksimasi kepuasan pelanggan dengan masih berupaya untuk meminimasi biaya operasional. CV. Transpatindo telah dapat melakukan maksimasi kepuasan pelanggan dengan masih berupaya untuk meminimasi biaya operasional sebagai efek samping dari upaya perusahaan dalam memaksimalkan kepuasan pelanggan, dimana hal tersebut dapat menjadi bekal perusahaan dalam menghadapi era masyarakat ekonomi Asean.

\section{Daftar Pustaka}

Gungor, 2000, Multiple Attribute Decision Making: Methods and Applications in Industries, Spinger

Gupta, 2004, The Psychology of Judgment and Decision Making II, Elsevier

Hwang, Y. (1981),Multiple Attribute Decision Making: Methods and Applications, Springer

Indrianti, N., Sutrisno, 2014, Buku Ajar Pengambilan Keputusan Multi Kriteria, UPN "Veteran" Yogyakarta, Yogyakarta

Kleindorfer, 2005, Sustainable Operations Management, Production and Operations Management, Volume 14, Issue 4, 482-492

Maystre , (1994), Méthodes multicritères ELECTRE, Lausanne: Presses Polytechniques.

Muhsin, 2014, Logika Pemrograman dan Dasar Komputer, Jurusan Teknik Industri UPN "Veteran" Yogyakarta, Yogyakarta

Plous, (1993), The Psychology of Judgment and Decision Making, Penn Libraries, University of Pennsylvania, Amerika Serikat

Ristono, 2011, Pemodelan Sistem, Graha Ilmu, Yogyakarta

Simon, (1983), Rational decision making in business organizations, American Economic Review 69: 493-513 